\title{
"GEOGRAFIAS DO SUL": DESCENTRAMENTO, TRANSESCALARIDADE E ESPACIALIZAÇÕES NO PENSAMENTO MILTONIANO
}

Gabriel Carvalho da Silva Leite ${ }^{1}$ Saint-Clair Cordeiro da Trindade Júnior ${ }^{2}$

Resumo: Nos últimos anos, o pensamento descolonial tem se afirmado como importante abordagem na ciência geográfica brasileira. Com vistas a contribuir com essa discussão contemporânea, o artigo identifica um conjunto de intelectuais cujas preocupações e reflexões se aproximaram, de alguma maneira, de problemáticas atualmente abordadas pelas "epistemologias do Sul", definindo a vertente aqui metaforicamente nomeada de "geografias do Sul". Após uma breve caracterização dos principais atributos dessa vertente, procura-se identificá-los nas obras de alguns importantes geógrafos brasileiros, com destaque para Milton Santos, autor cujo pensamento descentrado, transescalar e atento às geografizações da sociedade em muito tem a contribuir com a compreensão do "Sul global" no período atual.

Palavras-chave: Geografias do Sul. Epistemologias do Sul. Pensamento geográfico brasileiro. Milton Santos.

\section{“GEOGRAPHIES OF THE SOUTH”: DECENTRING, TRANSESCALARITY AND SPATIALIZATIONS IN THE MILTONIAN THOUGHT}

Abstract: In recent years, decolonial thought has asserted itself as an important approach in Brazilian geographical science. In order to contribute to this contemporary discussion, the article identifies a group of intellectuals whose concerns and reflections have somehow approached the problems currently addressed by the "epistemologies of the South", defining the strand here metaphorically named "geographies of the South". After a brief characterization of the main attributes of this strand, they are identified in the works of some important Brazilian geographers, with emphasis being placed on Milton Santos, an author whose decentralized, transcalar and geographically attuned thought has a lot to contribute to the understanding of the "global South" in the current period.

Keywords: Geographies of the South. Epistemologies of the South. Brazilian geographical thought. Milton Santos.

\section{“GEOGRAFÍAS DEL SUR”: DESCENTRAMIENTO, TRANSESCALARIDAD Y ESPACIALIZACIONES EN EL PENSAMIENTO MILTONIANO}

Resumen: En los últimos años, el pensamiento descolonial se ha afirmado como un enfoque importante en la ciencia geográfica brasileña. Para contribuir a esta discusión contemporánea, el artículo identifica a un grupo de intelectuales cuyas preocupaciones y reflexiones de alguna manera se acercaron a los problemas que

\footnotetext{
1 Universidade Federal do Pará, Núcleo de Altos Estudos Amazônicos, Belém, Brasil, gabrielcarvalholeite16@gmail.com, https://orcid.org/0000-0003-1690-3557.

2 Universidade Federal do Pará, Núcleo de Altos Estudos Amazônicos, Belém, Brasil, stclair@ufpa.br, https://orcid.org/0000-0001-6390-665X.
} 
actualmente abordan las "epistemologías del Sur", definindo la vertiente denominada metafóricamente "geografías del Sur". Después de una breve caracterización de sus principales atributos, tratamos de identificarlos en las obras de algunos importantes geógrafos brasileños, con énfasis en Milton Santos, un autor cuyo pensamiento descentrado, transescalar y atento a las geografizaciones de la sociedad tiene mucho que contribuir a la comprensión del "Sur global" en el período actual.

Palabras clave: Geografías del Sur. Epistemologías del Sur. Pensamiento geográfico brasileño. Milton Santos.

\section{Introdução}

Desde que foi proposto por Maldonado-Torres (2008), o conceito de "giro descolonial" tem sido utilizado para designar um movimento epistêmico-cognitivo e ético-político que se apresenta, em um primeiro momento, como um sentimento de horror e espanto ante a desumanização de comunidades e sujeitos sociais promovida pela modernidade-colonialidade, para, em um segundo momento, converter-se em uma postura crítica e comprometida com a superação desse estado de coisas.

Não obstante, em um sentido mais estrito que aquele proposto pelo filósofo porto-riquenho, a expressão "giro descolonial" tem sido utilizada como "uma forma sintética de nomear uma inflexão epistêmica, ética e política nas ciências sociais latino-americanas" (CRUZ, 2017, p. 23), deflagrada a partir dos esforços coletivos de um conjunto de intelectuais reunidos no grupo "Modernidade/Colonialidade" (M/C), fundado no final da década de 1990.

Compartilhando algumas premissas fundamentais - como a de que a colonialidade não é um subproduto contingente da modernidade, mas sim a sua "face obscura", existente e persistente mesmo após o fim do colonialismo - e um conjunto de conceitos e categorias de análise desenvolvidos ao longo de aproximadamente vinte anos de existência, a produção nesse sentido tem contribuído para a renovação do pensamento crítico latino-americano e para a constituição do campo dos estudos descoloniais.

A fundamentar grande parte desse pensamento está a contribuição de Sousa Santos (2009), que postula o exercício de descentramento como pressuposto para captar a totalidade do que está a ocorrer no mundo contemporâneo. Esse pressuposto requer, por sua vez, um esforço coletivo, em dois sentidos, para desenvolver o que denomina de "epistemologias do Sul" (SOUSA SANTOS, 2012). O primeiro é o "regresso do colonial e do colonizador", de natureza mais política, e 
que revela a transposição da linha de divisão imposta entre a metrópole e a colônia herdada do passado. O segundo é um contramovimento, chamado de "cosmopolitismo subalterno", que faz emergir um pensamento alternativo de resistência epistemológica associado à resistência política.

No intento de problematizar essa discussão no âmbito da trajetória da ciência geográfica, e especialmente da produção acadêmica da Geografia brasileira, cumpre aqui indagar as origens de um pensamento geográfico que, de alguma maneira, aproxima-se e que tenha em mente algumas dessas questões que envolvem a situação de subalternização de realidades como a da América Latina tanto quanto os problemas diretamente decorrentes dessa condição.

Embora não se pretenda desenvolver uma genealogia completa nos limites do presente artigo, intenta-se apresentar alguns subsídios para a discussão, expondo, na primeira seção, a presença de elementos ou atributos das "geografias do Sul" nas obras de importantes geógrafos brasileiros, para, em seguida, na segunda e na terceira seções, enfocar naquele que consideramos uma de suas maiores expressões, o intelectual baiano Milton Santos.

\section{As "geografias do Sul"}

Três atributos têm sido recorrentemente mencionados para falar de uma ciência crítica mais alinhada às questões regionais e locais do mundo contemporâneo: o descentramento, a transescalaridade e a geografização. Tais atributos também apontados por autores como Cruz (2017), no âmbito da ciência geográfica, encontram-se fortemente presentes nas reflexões de intelectuais brasileiros que compõem aquilo que estamos chamando de "geografias do Sul".

Embora sob perspectivas teóricas e metodológicas distintas daquelas adotadas pelas "epistemologias do Sul", esses geógrafos contribuíram com análises

\footnotetext{
${ }^{3}$ Utilizamos aqui essa denominação acompanhando a discussão de alguns autores que trataram do tema sob perspectiva semelhante. Dantas (2014), por exemplo, ao fazer aproximações entre as "epistemologias do Sul", de Boaventura de Sousa Santos, e a obra miltoniana, destaca que esta última tem como uma de suas principais preocupações a proposição de uma epistemologia geográfica adequada para a análise do "Sul". Cerqueira-Neto (2017), por seu turno, fala de uma "Geografia Popular", que nasce do encontro entre as já mencionadas "epistemologias do Sul" e a "Geografia Nova", de Milton Santos. Em resenha da obra "Milton Santos: a pioneer in critical geography from the global South" (MELGAÇO; PROUSE, 2017a), Machado (2019) aponta ser esse um livro provocativo exatamente por se voltar à exploração da riqueza de geografias que foram pensadas desde o "Sul". Da mesma maneira, Ferretti e Pedrosa (2018) discutem bem o papel ativo de Milton Santos enquanto um pensador do "Sul global" e, inclusive, traçam alguns paralelos entre a trajetória desse autor e a do também intelectual brasileiro Josué de Castro.
} 
descentradas, transescalares e atentas aos processos de geografização próprios às realidades nacionais e regionais periféricas que buscaram compreender.

A título de exemplo, o tema da fome no Brasil e o problema agrário nordestino e brasileiro despertaram a atenção de autores como Josué de Castro e Manuel Correia de Andrade, cujos olhares foram lançados a partir de um ângulo que permite ver a realidade brasileira na perspectiva de situações e problemas que lhe são muito particulares e que se associam a uma condição de exploração historicamente definida e bem identificada por esses autores em suas obras.

Em Josué de Casto, a temática da fome representa um esforço, já na década de 1940, de construção de uma Geografia integrada que permitisse uma visão de totalidade do Brasil de então, conforme pontua Moreira (2010), que reconhece nesse autor, com formação em Medicina, uma teoria geográfica de criação própria inspirada nos clássicos desta última ciência. Para além da inovação na forma de abordagem de um tema tão relevante, há, igualmente, a proposição de linguagem diferenciada para o tratamento da questão, conforme se observa no romance "Homens e caranguejos" (CASTRO, 2001), livro no qual o autor, com claro discernimento do fenômeno geográfico que envolve o tema, informa também as origens de sua preocupação:

procuro mostrar neste livro de ficção que não foi na Sorbonne, nem em qualquer outra universidade sábia, que travei conhecimento com a questão da fome. O fenômeno se revelou espontaneamente a meus olhos nos mangues do Capibaribe, nos bairros miseráveis da cidade do Recife: Afogados, Pina, Santo Amaro, llha do Leite. Esta que foi a minha Sorbonne: a lama dos mangues do Recife, fervilhando de caranguejos e povoada de seres humanos feitos de carne de caranguejo, pensando e sentindo como caranguejos (CASTRO, 2001, p. 10).

De forma mais específica ainda, o autor coloca a dependência colonial e o subdesenvolvimento como fundamentos de seus estudos:

o subdesenvolvimento não é, como muitos pensam equivocadamente, insuficiência ou ausência de desenvolvimento. O subdesenvolvimento é um produto ou subproduto do desenvolvimento, uma derivação inevitável da exploração econômica colonial ou neocolonial, que continua se exercendo sobre diversas regiões do planeta (CASTRO, 1951 apud ANDRADE, 2003, p. 74).

De outra maneira, argumenta:

a fome é para mim a expressão biológica de males sociológicos, estando em íntima relação com as distorções econômicas que denominei de subdesenvolvimento. O mapa do subdesenvolvimento, traçado segundo critérios técnicos, ajusta-se ao mapa da fome no mundo (CASTRO, 1984, p. 115 , grifo do autor). 
Em estudo sobre a obra e a trajetória intelectual desse autor, Azevedo (2014) identifica três fases de seu percurso intelectual. Em todas elas a preocupação com a dependência econômica e o subdesenvolvimento da América Latina se fazem presentes. Na primeira, o autor retrata principalmente o Nordeste, o problema da seca, da fome, da terra, da migração e do racismo. Na segunda, a escala de análise se amplia para o Brasil, reafirmando, nessa outra dimensão, elementos estruturais e demais temas vistos regionalmente no período anterior. Na terceira fase, já no exílio, o olhar sobre o Brasil é lançado a partir de sua condição de subdesenvolvimento, extensivo à América Latina como região explorada e com problemas históricos a serem solucionados; aí aparecendo, mais uma vez, temas como a fome, a concentração fundiária, a desigualdade, a subalternização e o subdesenvolvimento.

Não muito diferente é a contribuição de Manuel Correia de Andrade que, pautado inicialmente nas influências francesas da abordagem regional de Paul Vidal de La Blache, voltava seus estudos para uma geografia de cunho mais regionalista, mas com uma diferenciação muito clara da chamada geografia tradicional, dado o viés histórico-crítico nele muito presente, inspirado em matrizes teóricas preocupadas com questões sociais, e devido, também, o seu forte comprometimento político com o seu tempo e o seu espaço.

Em "A terra e o homem no Nordeste" (ANDRADE, 1986), uma de suas obras de maior expressão, esse geógrafo demarca mesmo uma transição na Geografia brasileira rumo a uma abordagem crítica que iria se robustecer especialmente a partir dos anos 1980. Conforme nos mostra Marino (2014), nela há o diálogo com diferentes campos do conhecimento, a superação dos estudos geográficos de cunho mais empirista, a preocupação com temas de ordem ambiental e, especialmente, a ênfase à dimensão política relacionada ao problema agrário e ao desenvolvimento regional, que revela o seu olhar e a sua preocupação com o ponto de vista e as lutas dos movimentos sociais.

Mais difundida ainda é a vasta produção de Milton Santos, conhecedor da obra de Josué de Castro e de Manuel Correia de Andrade. Santos figura, junto com esses e outros autores, como um dos principais expoentes, no Brasil, daquilo que estamos chamando de "geografias do Sul".

As atenções desse autor se voltaram para temáticas diversas, que consideram desde estudos do espaço intraurbano, a exemplo de suas obras sobre o centro da cidade de Salvador (SANTOS, [1959] 2008a) e da cidade de São Paulo (SANTOS, 
1990, 1994), inclui análises sobre o espaço brasileiro (SANTOS, 1993; SANTOS; SILVEIRA, [2001] 2012) e sobre os países "subdesenvolvidos", conforme se vê em Santos (1978, [1979] 2007, [1979] 2008b, [1978] 2013a), culminando com teorizações mais gerais a respeito do espaço e da Geografia como ciência (SANTOS, 1988, [1978] 2012, [1985] 2014a, [1987] 2014b, [1996] 2014c), bem como a respeito do atual período da história da humanidade, definido por processos de globalização (SANTOS, [2000] 2001, [1994] 2013b, [1996] 2014c).

É nesse sentido que a seção a seguir dedica-se a elucidar a presença dos elementos dessa vertente de abordagem no pensamento e na obra miltoniana.

\title{
O "Sul" no pensamento miltoniano
}

Em que pese o sentido metafórico do "Sul" e do "Norte global", o que aqui estamos reconhecendo como "geografias do Sul" traz a preocupação de compreender as relações de ordem mundial e global que repercutem em processos socioespaciais que interessam para o entendimento das expressões de poder entre os sujeitos que definem as configurações regionais contemporâneas; daí o sentido metafórico dado a essa denominação.

Igualmente, tais posicionamentos contribuem para uma tomada de consciência crítica a respeito da elaboração do conhecimento e do saber que se constrói nessas regiões, voltadas para elas próprias e a partir delas mesmas. Em vez de "geografismos" (LACOSTE, 1988), que dão protagonismo a espaços e territórios esvaziados de sujeitos históricos e suas relações, as preocupações voltam-se, sobretudo, para as relações de poder e para as "geografizações" que delas decorrem, conforme se faz perceber claramente na proposição teórica das "geografias do Sul", de Milton Santos:

\begin{abstract}
diríamos (...) que a sociedade está sempre espacializando-se. Mas a espacialização não é o espaço. A espacialização é um momento da inserção territorial dos processos sociais. O espaço é mais do que isso, pois funciona como um dado do próprio processo social (...) A espacialidade seria um momento das relações sociais geografizadas, o momento da incidência da sociedade sobre um determinado arranjo espacial. A espacialização não é o resultado do movimento da sociedade apenas, porque depende do espaço para se realizar. No seu movimento permanente, em sua busca incessante de geografização, a sociedade está subordinada à lei do espaço preexistente (SANTOS, 1988, p. 73-74).
\end{abstract}

Com base nesse entendimento, temos que as "geografizações" se apresentam como inscrições territoriais no presente dos processos sociais, resultando da combinação do movimento da sociedade com as configurações espaciais existentes. Essa é a leitura que Milton Santos estabelece para pensar o mundo desde uma 
perspectiva das regiões do "Sul", mas de uma forma que não as isola da totalidade da qual dialeticamente fazem parte, não obstante a existência de espacialidades diferenciadas que naquelas regiões se configuram.

Tal preocupação o instigou muito mais a uma renovação do ponto de vista metodológico que propriamente à proposição de uma ou outra geografia voltada para o "Norte" ou para o "Sul global"; pelo menos é o que o autor deixa claro desde o seu clássico livro "O trabalho do geógrafo no Terceiro Mundo" (SANTOS, 1978), quando ainda se falava do binômio países "subdesenvolvidos" e países industrializados:

não se deduza... que a nossa ótica em relação aos países subdesenvolvidos implica uma doutrina ou metodologia diferente daquela aplicada aos países industrializados. Se os objetos são vários e até mesmo contraditórios, a verdade é que os dados da economia mundial abarcam, num só conjunto de causas e efeitos, todos os eventos que ocorrem na superfície do globo. Se estivermos de acordo quanto a esse ponto de vista, será igualmente difícil ou mesmo impossível propor uma geografia dos países subdesenvolvidos em oposição a uma geografia dos países industrializados. De fato, a Geografia é uma só, e as variáveis que criam as diferenças no espaço entre países industrializados e países subdesenvolvidos não poderão jamais desfazer a profunda unidade das causas fundamentais (SANTOS, 1978, p. 33).

Daí a indagação feita pelo autor na mesma obra a partir dos seguintes termos: quais são os principais problemas a serem resolvidos na renovação da geografia humana e como enfrentá-los desde o Terceiro Mundo? Questionamentos como esses sinalizam, nessa e também em outras obras do autor, para a construção de uma geografia de bases latino-americanas (HIERNAUX, 2008).

É dessa forma que ainda na mesma obra Santos faz a crítica ao empirismo da Geografia francesa da época, coloca a necessidade de bases teóricas para pensar o espaço e, fundamentalmente, empreende a construção de um pensamento focado na leitura dos países "subdesenvolvidos"; e isso é feito reconhecendo o papel de seus mestres europeus e, ao mesmo tempo, definindo uma Geografia própria (PEDROSA, 2018).

Rumo a essa tarefa, que pressupunha a renovação metodológica, ao longo de sua produção acadêmica, várias são as discussões teóricas que o encaminham para esses objetivos, chegando a contribuir com uma teoria do subdesenvolvimento, com uma teoria do espaço, assim como, com uma teoria para a Geografia e, a partir desta, com uma teoria mais geral para pensar a sociedade no interior da qual o espaço é entendido como uma de suas instâncias (SANTOS, [1978] 2012). 
É em alicerces como esses que se edificam as suas "geografias do Sul". Neles se constrói um olhar não necessariamente eurocêntrico do mundo, traduzido em sua obra como uma geografia do mundo e das desigualdades capitalistas. Por meio dela, lança-se o olhar e se dá especial atenção às realidades socioespaciais do subdesenvolvimento; aí incluindo a sua preocupação em entender o Brasil, como também os demais países da América Latina, da Ásia e da África; realidades essas por onde transitou ao longo de sua experiência acadêmica e intelectual em nível internacional.

\section{Descentramento, transescalaridade e geografização em Santos}

O geógrafo Milton Santos é amplamente reconhecido como um dos principais nomes do movimento de renovação crítica da Geografia brasileira, iniciado no final da década de 1970 e robustecido a partir dos anos 1980. Na presente seção, procuraremos demonstrar que esse importante intelectual também pode ser considerado um expoente das "geografias do Sul" no Brasil, na medida em que as teorizações e formulações presentes em sua obra: a) operam um descentramento do olhar para as experiências dos países "subdesenvolvidos", em particular do Brasil, a partir dos quais refletiu, teorizou e dialogou criticamente com o pensamento de matriz europeia; b) expressam uma abordagem transescalar, preocupada com a apreensão e a articulação de múltiplas escalas espaciais e temporais; e c) conferem ao espaço a condição de categoria analítica imprescindível à compreensão da geografização dos processos de dominação, exploração e resistência que caracterizam as sociedades subalternizadas em suas relações internas e naquelas mantidas com outras sociedades.

Embora o descentramento tenha sido um atributo importante do pensamento miltoniano desde os primeiros estudos desenvolvidos pelo autor no Estado da Bahia, foi somente a partir da experiência do exílio, iniciada em 1964, que esse atributo se mostrou mais evidente. Isso porque, imerso no ambiente intelectual francês no qual foi inicialmente acolhido, e posteriormente também inserido em instituições de ensino e pesquisa nos Estados Unidos e no Canadá, Milton Santos passou a se dedicar mais sistematicamente ao estudo da organização do espaço e da urbanização no chamado "Terceiro Mundo", gradativamente se distanciando dos pressupostos iniciais da Geografia Regional francesa e do mainstream dos debates sobre o subdesenvolvimento que se faziam presentes naqueles países. 
A insatisfação do geógrafo brasileiro com as interpretações então dominantes sobre a economia, a urbanização e a organização espacial dos países do "Terceiro Mundo" motivou-o a um esforço de elaboração teórica própria e original, sistematicamente desenvolvido ao longo dos anos 1960, e cuja culminância deu-se com a proposição da teoria dos circuitos da economia urbana dos países "subdesenvolvidos", na década de 1970. Segundo informou o próprio autor em entrevista a Jesus de Paula Assis e Maria Encarnação Sposito, a elaboração dessa teoria respondeu a uma necessidade de "repensar a geografia do Terceiro Mundo":

quando vou ensinar na França, cria-se realmente o primeiro choque, porque compreendo que não podia continuar ensinando do jeito clássico e começo a repensar a geografia do Terceiro Mundo. Percebo que ela não cabe naquele esqueleto intelectual e começo a me perguntar como sair daquilo, como propor sem chocar (...) Tudo isso deriva da vontade de explicar nossos países para o pessoal lá no Norte. Como brasileiro e do Nordeste, entendi que a indústria não era uma explicação suficiente. $E$ por aí cheguei à minha teoria dos dois circuitos. A fratura foi se dando de forma construída, sub-reptícia, sem ruptura com as teorias assentes e com o próprio marxismo clássico (SANTOS, 2004, p. 19-20).

Em "O espaço dividido: os dois circuitos da economia urbana dos países subdesenvolvidos" (SANTOS, [1979] 2008b), obra na qual a teoria dos circuitos foi apresentada de forma mais completa e sistemática, o autor criticou a insuficiência das abordagens "adjetivas" sobre a urbanização no "Terceiro Mundo", as quais, por pressuporem uma similaridade das trajetórias históricas dos países "desenvolvidos" e "subdesenvolvidos", aplicavam irrefletidamente os conceitos elaborados a partir daqueles primeiros à realidade destes últimos, permanecendo, dessa maneira, tributárias de uma perspectiva exterior aos processos que buscavam compreender. Santos defendeu, então, a necessidade de abordagens verdadeiramente "substantivas", voltadas à investigação da especificidade histórica, econômica, social e geográfica do subdesenvolvimento:

seria mais honesto substituir essa aplicação irrefletida de conceitos ocidentais e essa obsessão de comparação com as situações do mundo desenvolvido por uma dimensão mais justa, a histórica, que leve primeiro à compreensão do processo de subdesenvolvimento. (...) O estudo da história dos países hoje subdesenvolvidos permite revelar uma especificidade de sua evolução em relação às dos países desenvolvidos. Essa especificidade aparece claramente na organização da economia, da sociedade e do espaço e, por conseguinte, na urbanização, que se apresenta como um elemento numa variedade de processos combinados (SANTOS, [1979] 2008b, p. 18-19).

A partir de uma leitura que conferiu centralidade às desigualdades socioespaciais e ao caráter seletivo das modernizações tecnológicas e organizacionais no "Terceiro Mundo", Santos ([1979] 2008b) defendeu que o estudo 
da urbanização e da organização do espaço nos países "subdesenvolvidos" deveria levar em consideração a segmentação estrutural de suas economias urbanas em circuitos de fabricação, distribuição e consumo bastante diferenciados entre si, sendo um deles - o circuito superior - diretamente associado às modernizações tecnológicas e aos esquemas corporativos de reprodução econômica; e o outro - o circuito inferior - associado às formas de reprodução social das populações mais pobres, usualmente mais dependentes do trabalho que do capital.

No contexto em que foi proposta, a teoria dos circuitos da economia urbana representou uma interpretação original sobre os países "subdesenvolvidos" e um esforço para compreender as suas dinâmicas espaciais e urbanas a partir de parâmetros que lhes são próprios, sem recorrer às comparações e adjetivações que se faziam frequentes nos estudos sobre o "Terceiro Mundo". Exemplo dessa perspectiva descentrada foi o tratamento conferido por Santos ([1979] 2008b) às formas de reprodução social características da pobreza urbana, usualmente confundidas com o dito "setor terciário" e qualificadas como "estacionárias", "parasitárias" ou "irracionais" pelo mainstream da literatura econômica de então.

Alternativamente, o autor propôs entender que esse conjunto de atividades de fabricação artesanal, de pequenos comércios e serviços e de transportes nãomodernos - não redutíveis, portanto, ao "setor terciário" - constitui um sistema econômico dotado de características muito particulares e cujos dinamismos e mecanismos de funcionamento frequentemente escapam às teorias e aos conceitos elaborados a partir da realidade europeia ou norte-americana.

Outrossim, Santos ([1978] 2013a) considerou que o uso da expressão "setor informal", muito difundida internacionalmente desde seu aparecimento no início da década de 1970, para referir-se às atividades do circuito inferior, associava-se muito fortemente à ideia de irracionalidade, em contraposição com aqueles empreendimentos que dispunham de uma organização dita "formal", entendida como racional, no sentido weberiano do conceito. Para o autor, essa perspectiva etnocêntrica acaba por não reconhecer a racionalidade particular do circuito inferior, adaptada às condições de trabalho, de consumo, de crédito e de infraestrutura sob as quais operam as "economias pobres" dos países "subdesenvolvidos":

quando se referem a países subdesenvolvidos, os dualistas crêem (sic) numa oposição entre o setor desenvolvido e o não desenvolvido, um contraste entre um todo coerente de ações eficientes e racionais e um conjunto inarticulado de ações arcaicas, irracionais e ineficientes. (...) $\mathrm{O}$ caráter ideológico e etnocêntrico da distinção é óbvio. A noção de 
racionalidade que se procura aplicar como gabarito às sociedades préindustriais é um caso típico de arrogância cultural (...) Realmente, conforme realçou Godelier (1967, p. 298), não existe apenas uma racionalidade econômica, mas diversas (SANTOS, [1978] 2013a, p. 65-66, grifos do autor).

Ademais, é importante mencionar que a proposição da teoria dos circuitos da economia urbana, durante a década de 1970, foi contemporânea aos debates latinoamericanos em torno da noção de "marginalidade". Segundo Simoni-Santos (2017), a emergência dessa noção no meio intelectual do subcontinente deveu-se às críticas, por um lado, à abordagem liberal da pobreza e, por outro lado, à aplicação irrestrita da teoria das classes sociais, em sua versão clássica, aos países da América Latina. Para intelectuais como José Nun, Luiz Pereira e Manuel Castells autores de obras decisivas para os debates sobre a "marginalidade" - a teoria clássica das classes sociais não era capaz de um "reconhecimento da reprodução duradoura de um grupo social não alinhado à clássica divisão entre capitalistas e operários" (SIMONI-SANTOS, 2017, p. 2).

$\mathrm{Na}$ conhecida formulação de Nun (1969), esse grupo social corresponde ao que denominou de "massa marginal", uma fração da superpopulação relativa que, diferentemente do "exército industrial de reserva", é caracterizada pela falta de funcionalidade em relação aos fins da acumulação capitalista na América Latina. Não menos importantes foram as publicações das obras "A questão urbana" (CASTELLS, [1972] 1983) e "Imperialismo y urbanización en América Latina" (CASTELLS, 1973), cujas discussões contribuíram decisivamente para a colocação das problemáticas do imperialismo e da dependência econômica no centro da explicação da "marginalidade", considerada como um elemento da especificidade latino-americana.

Conforme aponta Simoni-Santos (2017), a perspectiva funcional-estruturalista dessas abordagens da "marginalidade" suscitou críticas por parte da tradição marxista brasileira, direcionadas, sobretudo, ao que julgava ser uma concepção dualista que impedia uma correta apreensão da totalidade social. Simoni-Santos (2017) menciona, dentre os intelectuais brasileiros que desenvolveram essas contundentes críticas ao dualismo da teoria da "marginalidade", os sociólogos Fernando Henrique Cardoso e Francisco de Oliveira e o geógrafo Milton Santos. Este último autor, embora reconhecesse a importância e o pioneirismo da elaboração teórica de Quijano (1973) a respeito do conceito de "polo marginal", vinha construindo, desde pelo menos o início da década de 1970, uma perspectiva 
crítica aos pressupostos dualistas da noção de "marginalidade", os quais insistiam em julgar a dita "massa marginal" como disfuncional à acumulação capitalista.

A partir da teoria dos circuitos da economia urbana, Santos ([1979] 2008b) procurou mostrar que as formas de trabalho usualmente classificadas como "marginais" são integrantes de um circuito econômico que não está apartado dos processos mais gerais de acumulação capitalista, bem como que essas mesmas formas são, tanto quanto o circuito superior, produtos das condições de inserção dos países "subdesenvolvidos" no sistema capitalista internacional e da correspondente adoção dos novos modelos tecnológicos de produção, distribuição e consumo, embora se configurem mais como seus produtos indiretos. Há, portanto, na perspectiva teórica proposta pelo autor, uma ruptura com os dualismos tradicional/moderno, capitalista/pré-capitalista e/ou funcional/disfuncional, evidente no reconhecimento dos efeitos globais das modernizações tecnológicas e das múltiplas formas de articulação entre os circuitos da economia urbana.

Além do diálogo crítico travado com os teóricos da "marginalidade", Milton Santos também levou em consideração outros debates que, à época, tinham lugar nas ciências sociais latino-americanas, a exemplo da teoria da dependência, notadamente em sua "versão" marxista, desenvolvida por Ruy Mauro Marini e por outros intelectuais da Política Operária (POLOP). Formulada, sobretudo, durante os anos de exílio de Marini, a teoria que ficou conhecida como "dialética da dependência", assentada nas ideias de "superexploração do trabalho" e de "subimperialismo"4, representou o principal contraponto à versão da teoria da dependência defendida por Fernando Henrique Cardoso e Enzo Faletto, tendo exercido importante influência no pensamento crítico latino-americano durante os anos 1970 .

Conforme aponta Machado (2017), a maior aproximação de Milton Santos ao debate do "subimperialismo" deu-se por ocasião de sua participação no evento "Conference on external dependence and problems of development in Latin America

\footnotetext{
${ }^{4}$ Segundo Machado (2017), a teoria de Ruy Mauro Marini compreendia a industrialização latinoamericana em geral, e brasileira em particular, como um processo marcado pela dependência em relação a mercados externos, de maneira que, não sendo o capital industrial dependente do mercado interno para consumo de seus produtos, era-lhe possível pressionar os salários dos trabalhadores para baixo, chegando a níveis que caracterizavam uma verdadeira "superexploração do trabalho". Adicionalmente, no contexto de dependência tecnológica em que ocorria a industrialização, o endividamento externo e o desequilíbrio gerado na balança comercial faziam mister a atuação do Estado no subsídio aos setores exportadores e monopolistas, bem como na adoção de estratégias "subimperialistas" para resolução dos problemas de acumulação capitalista, com base na expansão de capitais para outros países da América Latina.
} 
and the Caribbean", realizado na Universidade de Toronto, em abril de 1972, e no qual também estiveram presentes outros intelectuais latino-americanos, como Aníbal Quijano, José Nun, Octávio lanni e Ruy Mauro Marini.

Encarregado de comentar a palestra deste último autor sobre o "subimperialismo" brasileiro no subcontinente, Santos desenvolveu uma reflexão, posteriormente publicada em coletânea organizada por aquela universidade (SANTOS, 1975), a propósito da correspondência entre o fenômeno tratado por Marini e os países que qualificou como "subdesenvolvidos industrializados", cujas industrializações dependentes e orientadas para o setor externo, ao entravarem o desenvolvimento de indústrias propriamente nacionais, estimulam a expansão subimperialista de bens de consumo e de capital sobre os mercados de países vizinhos.

Paralelamente à sua inserção em importantes discussões das ciências sociais latino-americanas durante a década de 1970, Milton Santos também não deixou de estabelecer diálogos críticos com o pensamento europeu, notadamente com aquelas teorias que então orientavam os esforços de planejamento econômico, regional e urbano nos países do "Terceiro Mundo". Sem ignorá-las ou descartá-las completamente, Santos propôs revisões de influentes proposições teóricas da economia espacial, como a dos lugares centrais, de Walter Christaller, e a dos polos de crescimento, de François Perroux, à luz da especificidade da organização do espaço e da economia nos países "subdesenvolvidos".

No que concerne à teoria dos lugares centrais, Santos ([1979] 2007) considerou que, embora meritória por seus esforços pioneiros no campo dos estudos da rede urbana, ela não poderia ser transposta sem adaptações à realidade dos países "subdesenvolvidos", nos quais a segmentação da economia em dois circuitos de fluxos impede de se falar em apenas um urban field, à maneira de Christaller. Para o autor, o fato de que os circuitos da economia estejam presentes em todos os escalões da rede urbana, embora com importâncias, volumes e complexidades diferenciadas, demanda uma revisão da teoria christalleriana. Isso porque, no "Terceiro Mundo", em vez de um único alcance, "toda cidade tem duas áreas de influência de tamanhos diferentes e cada uma delas varia em função do tipo de aglomeração bem como dos procedimentos de cada circuito" (SANTOS, [1979] 2007, p. 131). 
Assim, levando em consideração as diferenças de natureza e de operação entre os circuitos da economia urbana, Santos ([1979] 2007) propôs entender que o circuito superior dispõe de maior alcance nas metrópoles, pois essas aglomerações exercem o essencial de sua centralidade a partir das atividades modernas, enquanto que nas cidades locais, o limiar e o alcance desse circuito são meramente hipotéticos. O circuito inferior, pelo contrário, embora seja bastante presente nas metrópoles, dado o fato de serem elas polos atrativos da pobreza, dispõe de maior alcance nas cidades locais, sendo, por vezes, o único responsável pela oferta de determinados bens e serviços básicos em localidades nas quais o circuito superior não atua.

A importância da revisão da teoria christalleriana com base nos circuitos da economia urbana é reconhecida por Corrêa (1988, p. 77), que afirma que "sem excluir a teoria das localidades centrais, a contribuição de Santos, na realidade, ultrapassa-a, enriquecendo-a". Esse autor acrescenta, ainda, que a teoria miltoniana dos circuitos confere uma dimensão política ao estudo das redes de lugares centrais, pois leva em conta os significados diferenciais que a rede urbana assume em função das grandes desigualdades de renda nos países "subdesenvolvidos".

Outra importante crítica de Milton Santos às formulações da economia espacial de matriz europeia foi direcionada à teoria dos polos de crescimento, originalmente formulada nos anos 1950, pelo economista francês François Perroux, e amplamente difundida no âmbito acadêmico e em experiências de planejamento urbano e regional nas décadas seguintes. As formulações teóricas de Perroux a respeito do processo desequilibrado de crescimento das economias nacionais e do papel das indústrias motrizes e dos clusters na indução de efeitos propulsores pelo território foram fontes inspiradoras para técnicos e planejadores que, durante os anos 1960 e 1970, adaptaram-nas e as instrumentalizaram em estratégias de planificação regional pautadas na criação e fomento de polos de crescimento ou de desenvolvimento econômico.

Para Santos ([1979] 2007), essa coincidência temporal da difusão da teoria perrouxiana com o auge do planejamento capitalista nos países "subdesenvolvidos" em muito contribuiu para o empobrecimento analítico da proposta do economista francês, frequentemente reduzida a um instrumento destinado a legitimar objetivos preestabelecidos. Daí a perspectiva parcial e dualista de muitas das formulações derivadas da teoria dos polos de crescimento, as quais transpareciam uma certa 
independência do espaço econômico em relação ao espaço "banal", como se as relações e as estruturas de ordem econômica não repercutissem no espaço vivido por toda a população. Para o autor, a utilização disseminada das matrizes de insumo-produto para medição das interrelações entre "indústrias motrizes" e "indústrias movidas", em detrimento de uma abordagem integral do espaço, que considere as relações entre a estrutura de produção e as demais estruturas sociais, demonstrava que:

(...) no mais das vezes, as construções teóricas e os esforços de planejamento têm sido orientados para o espaço econômico. Desta forma, na maior parte de suas formulações tradicionais e recentes, a teoria dos pólos (sic) de crescimento tem se preocupado com o espaço de alguns poucos e não com o espaço de todos. Quando o espaço das grandes empresas se diferencia do espaço banal e é favorecido na elaboração teórica, o resultado natural é uma teoria aristocrática e discriminatória, porque a população quase não é levada em conta (SANTOS, [1979] 2007, p. 167).

Outrossim, para o autor, não apenas as aplicações da teoria dos polos de crescimento deixavam de considerar outras estruturas sociais, para além da econômica, como também costumavam levar em conta somente a fração mais modernizada desta última, negligenciando todo o restante da economia. Conforme Santos ([1979] 2007), a ênfase conferida pelo planejamento urbano e regional ao circuito superior ignorava que, nas condições em que se encontravam os países "subdesenvolvidos", a instalação pontual das atividades mais modernas naqueles pontos privilegiados que já contavam ou que eram intencionalmente equipados com economias externas era incapaz de exercer os efeitos multiplicadores previstos pela teoria.

Como resultado da situação descrita acima, seria possível, e mesmo muito frequente, haver "crescimento sem polos de crescimento" (SANTOS, [1979] 2007), uma vez que as quantidades globais da economia poderiam conhecer aumento sem que os núcleos urbanos escolhidos pelas atividades modernas exercessem verdadeiros efeitos multiplicadores. Em verdade, como bem demonstrou o autor, a atuação do circuito superior nessas cidades restava incapaz de abrigar toda a população, fazendo com que, no interior mesmo do "polo", o circuito inferior pudesse se instalar e assumir importância, demonstrando que "o crescimento econômico e o desenvolvimento do circuito inferior ocorrem de maneira paralela" e que aquele primeiro "não aparece como o processo capaz de eliminar a pobreza" (SANTOS, [1979] 2007, p. 174). 
Essas e outras contribuições de Milton Santos fundamentaram a sua crítica radical ao papel que o planejamento e as ciências econômicas e espaciais vinham desempenhando, por meio de suas formulações teórico-conceituais e das sistemáticas de intervenção e planificação difundidas no pós-Segunda Guerra Mundial, na manutenção e no aprofundamento da dependência, do subdesenvolvimento e da pobreza no "Terceiro Mundo" (SANTOS, [1979] 2007). Para Ferretti e Pedrosa (2018), essa postura assumida por Santos exemplifica a atuação decisiva que os intelectuais do "Sul global" tiveram, a partir dos seus respectivos loci de enunciação, na produção de "contra-teorizações" no campo dos estudos sobre o desenvolvimento, lançando as sementes das perspectivas críticas que, posteriormente, ganhariam maior terreno sob a denominação de "critical development studies".

Ademais, as contribuições de Milton Santos durante a década de 1970 não se limitaram ao âmbito dos estudos sobre a urbanização no "Terceiro Mundo", mas também incluíram a própria teoria social crítica, notadamente de matriz marxista. No livro "Por uma Geografia nova: da crítica da Geografia a uma Geografia crítica" (SANTOS, [1978] 2012), marcado por uma contundente condenação da vinculação histórica da ciência geográfica aos projetos colonialistas e imperialistas dos países europeus, o autor apresentou, de forma mais sistematizada, uma elaboração teórica original a respeito do espaço como uma instância da sociedade.

Na proposta de Santos ([1978] 2012), para além das estruturas econômica, jurídico-política e ideológico-cultural - mais classicamente reconhecidas pelo pensamento marxista -, o espaço também deve ser considerado como uma instância da sociedade, cuja especificidade é dada pela tendência à reprodução ampliada de seus traços dominantes; pelo seu caráter subordinado-subordinante; pela autonomia relativa de que dispõe frente às outras instâncias; e, sobretudo, pela sua inércia dinâmica, isto é, pelo fato de que a sua materialidade - as formas geográficas - corporifica o passado no presente, condicionando o movimento atual da sociedade e, ao mesmo tempo, oferecendo resistência às transformações das outras estruturas sociais.

Essa concepção dialética que reconhece o papel central do espaço nos processos sociais e, ao mesmo tempo, o insere na totalidade da qual faz parte, permitiu ao autor afastar-se dos "geografismos", contra os quais alertava Lacoste (1988), e chegar efetivamente às "geografizações", entendidas enquanto inscrições 
territoriais no presente dos processos sociais, resultantes da combinação do movimento da sociedade com as configurações espaciais existentes.

Um exemplo bastante representativo dessa orientação teórica foi a proposta de Milton Santos, desenvolvida durante a década de 1980 e mais sistematicamente apresentada em "O espaço do cidadão" (SANTOS, [1987] 2014b), a propósito do que denominou de "modelo cívico-territorial", fundado, dentre outros princípios, na "geografização da cidadania", isto é, na conversão da cidadania abstrata em cidadania concreta mediante um planejamento, uma gestão e um ordenamento do território voltados à redistribuição equitativa dos recursos sociais e à atribuição de bens e serviços essenciais a todos os seus habitantes.

Outro exemplo que explicita o tratamento analítico conferido ao espaço na obra miltoniana é o conceito de meio técnico-científico informacional, elaborado pelo autor ao longo das décadas de 1980 e 1990 para dar conta da efetiva geografização do processo de globalização nos territórios nacionais (SANTOS, [1996] 2014c). Na leitura do autor, enquanto instância social, o espaço - naquelas suas porções que se apresentam dotadas de maiores cargas de técnica, ciência e informação - aparece tanto como um produto da globalização quanto como uma condição de sua plena realização.

É nesse sentido, por exemplo, que devem ser entendidos conceitos e noções como os de "produtividade espacial" e de "racionalidade do espaço" (SANTOS, [1996] 2014c), ambos sugerindo que as ações hegemônicas que dirigem a globalização contemporânea não dispensam determinados arranjos territoriais precisa e intencionalmente criados e localizados, dos quais dependem para as suas mais completas eficácias. Outrossim, as noções de "espaços que mandam" e "espaços que obedecem" - que, à primeira vista, parecem incorrer em "geografismos" - não são mais que metáforas que buscam expressar a indissociabilidade entre sistemas de objetos e sistemas de ações na produção das novas desigualdades territoriais e na espacialização das relações de poder no período da globalização (SANTOS; SILVEIRA, [2001] 2012).

A teoria do espaço como instância social também fundamenta a revisão da própria ideia de escala, bastante tradicional na Geografia, à luz das noções de evento e de tempo. Embora não tenha chegado a desenvolver plenamente essa formulação, Santos ([1996] 2014c) propôs que a escala poderia referir-se a pelo menos duas situações distintas, a saber: a escala das "forças operantes" e a escala 
de ocorrência. Na primeira se encontra a origem das variáveis envolvidas na produção do evento; na segunda, também chamada de escala do fenômeno, dá-se a "geografização" do evento.

$\mathrm{Na}$ primeira acepção, trata-se de eventos solidários (interdependentes), mas não superpostos, definindo uma solidariedade de tipo organizacional. Na segunda acepção, por seu turno, trata-se de eventos que, a despeito das suas escalas de origem diferenciadas, geografizam-se em uma mesma área comum, estabelecendo entre si uma solidariedade cujo fundamento é a contiguidade espacial, uma solidariedade de tipo orgânico. Para Santos ([1996] 2014c), pensar a escala à luz dessa segunda acepção pode ajudar a superar a excessiva rigidez da noção geralmente associada a determinadas extensões espaciais, em uma perspectiva absoluta do espaço (HARVEY, 1980) -, concebendo-a, em vez disso, como o subespaço do acontecer solidário, isto é, como áreas de dimensão variável, cujos limites são dados pela geografização dos eventos.

Santos ([1996] 2014c, p. 152) afirma que, quando pensada dessa maneira, a escala "é um dado temporal e não propriamente espacial; ou, ainda melhor, que a escala varia com o tempo, já que a área de ocorrência é dada pela extensão dos eventos". Nesse mesmo sentido, poderíamos também dizer que, na proposição do autor, a escala deixa de ser concebida a partir da perspectiva do espaço absoluto e é ressignificada enquanto espaço relacional (HARVEY, 1980), não fixada em recortes convencionais e tanto mais mutável e dinâmica quanto mais a globalização acelera a diferenciação dos eventos.

Assim, se a escala é entendida a partir dos eventos, e se estes são os vetores que transportam a totalidade-mundo aos distintos subespaços (regiões, lugares etc.), não há como falar de uma escala isoladamente sem implicar as outras. Coerente com o seu entendimento acerca da totalidade, Santos ([1978] 2012) defende ser necessário levar em conta o papel da acumulação de capital em escala mundial e as suas repercussões nas diversas escalas geográficas, inclusive em termos de divisão social e territorial do trabalho e da resultante hierarquização do espaço. Essa postura teórico-metodológica permitiu ao autor afastar-se de abordagens demasiadamente centradas em uma ou outra escala - como a local, por exemplo - e o levou a concluir que "para apreender essa nova realidade do lugar, não basta adotar um tratamento localista, já que o mundo se encontra em toda parte" (SANTOS, [1996] 2014c, p. 314). 
Trata-se, portanto, de uma leitura eminentemente transescalar e que se faz presente no entendimento do autor a respeito dos lugares como depositários finais dos eventos (SANTOS, [1996] 2014c) e das regiões como lugares funcionais do todo, loci "de determinadas funções da sociedade total em um momento dado" (SANTOS, [1985] 2014a, p. 89); como as diferentes versões da mundialização (SANTOS, 1988); e, também, como produtos do entrecruzamento de verticalidades e horizontalidades (SANTOS, 2003).

Além disso, o atributo da transescalaridade não se refere apenas ao espaço propriamente dito, mas também diz respeito aos horizontes temporais, embora ambas as dimensões sejam, de fato, indissociáveis. Em um de seus principais livros teóricos, "A natureza do espaço: técnica e tempo, razão e emoção" (SANTOS, [1996] 2014c), o autor diferencia, de um lado, a diacronia - o eixo das sucessões, que permite identificar distintos períodos - e, por outro lado, a sincronia, o eixo das coexistências, no qual os eventos ocorrem simultaneamente e "a vida social, em suas diferenças e hierarquias, dá-se segundo tempos diversos que se casam e se anastomosam, entrelaçados no chamado viver comum" (SANTOS, [1996] 2014c, p. 159). Para o autor, é, sobretudo, essa última concepção do tempo que deveria constituir a base do estudo geográfico.

Esse entendimento é importante para chegar às noções de "tempos rápidos" e "tempos lentos", propostas por Santos ([1996] 2014c) para a apreensão dos diferentes usos do território e do tempo social pelos indivíduos, empresas e instituições. Diferentemente do que sugeriam os discursos apologéticos da globalização que então se exaltava, o autor fez um "elogio da lentidão" (SANTOS, 2002), apontando para a necessidade de submeter a velocidade a critérios de cidadania social, econômica e política e propondo pensar o território nacional como um abrigo no qual, em cada região e em cada lugar, as combinações regionais e locais de técnicas, velocidades e ritmos pudessem permitir o bem-estar coletivo. Nos "tempos lentos", o autor via as possibilidades de conceber outros futuros possíveis, para além daquele imposto pelo "pensamento único" da globalização:

a literatura que glorifica a potência inclui a velocidade como força mágica que permitiu à Europa civilizar-se primeiro e empurrar, depois, a "sua" civilização para o resto do mundo. Se velocidade é força, o pobre, quase imóvel na grande cidade, seria o fraco (...) Creio, porém, que na cidade, na grande cidade atual, tudo se dá ao contrário. A força é dos "lentos" e não dos que detêm a velocidade (...) Nosso esforço deve ser o de buscar entender os mecanismos dessa nova solidariedade fundada nos tempos lentos da metrópole, que desafia a perversidade difundida pelos tempos rápidos da competitividade (SANTOS, [1994] 2013b, p. 79-82). 
Ademais, é notável que a teoria da globalização proposta por Santos, embora aspire certa universalidade, opera um verdadeiro esforço de descentramento interpretativo do fenômeno analisado, pois o "Sul global" comparece muito claramente como seu locus de enunciação. Para Melgaço e Prouse (2017b), essa é a principal contribuição do livro "Por uma outra globalização: do pensamento único à consciência universal”, concebido por Santos ([2000] 2001, p. 11) como uma "reflexão independente sobre o nosso tempo" e como uma "vontade de explicar os problemas e dores do mundo atual”, esforços esses que são conduzidos, sobretudo, a partir da perspectiva dos países e povos subalternizados. Por essa razão, Melgaço e Prouse (2017b) consideram que o livro em referência, publicado pela primeira vez em 2000, ofereceu uma necessária teoria alternativa da globalização, em um contexto em que as discussões acadêmicas sobre o tema eram dominadas pelas universidades europeias e norte-americanas.

Talvez em razão desse olhar descentrado sobre o fenômeno, Santos ([2000] 2001) retratou uma globalização bastante menos edulcorada que aquela sugerida pelo mainstream do momento, apontando que as "fábulas" que fazem crer em um mundo unido, homogêneo, desterritorializado e acessível a todos escamoteiam a perversidade sistêmica de um processo que tem produzido, para a grande maioria dos países e das populações, uma dependência e uma subordinação crescentes, um empobrecimento cumulativo, uma degradação da ideia de solidariedade em prol da naturalização da competitividade e uma perda desenraizadora de referenciais culturais, territoriais e de sociabilidade.

No entanto, se fábula e perversidade constituem duas faces de um mesmo processo, um pensamento dialético permitiu ao autor identificar, ainda, uma terceira tendência que emerge da contradição daí decorrente, a saber, a globalização como possibilidade. Para Santos ([2000] 2001), essa "outra globalização", exortada no título da obra, seria um projeto no qual assumiriam centralidade os países e os povos do "Sul global", precisamente porque são eles os membros mais frágeis da globalização atual, os menos beneficiados pela produção da "mais-valia mundial", as maiores vítimas das consequências da dependência e do imperialismo e os menos plenamente inseridos na materialidade e na racionalidade modernas, de maneira que dispõem de uma diversidade sociogeográfica que pode ser a base de uma globalização mais humana: 
na Ásia, na África e mesmo na América Latina, a vida local se manifesta ao mesmo tempo como uma resposta e uma reação a essa globalização. Não podendo essas populações majoritárias consumir o Ocidente globalizado em suas formas puras (financeira, econômica e cultural), as respectivas áreas acabam por ser os lugares onde a globalização é relativizada ou recusada. Uma coisa parece certa: as mudanças a serem introduzidas, no sentido de alcançarmos uma outra globalização, não virão do centro do sistema, como em outras fases de ruptura na marcha do capitalismo. As mudanças sairão dos países subdesenvolvidos (SANTOS, [2000] 2001, p. 153-154).

A "centralidade da periferia" a que se refere o autor é tanto o resultado desse papel a ser desempenhado pelos países ditos "subdesenvolvidos", quanto um produto da consciência de que o projeto "terceiro-mundista" - que tivera seu auge nas décadas de 1950 e 1960, capitaneado por intelectuais, políticos e ativistas do "Terceiro Mundo" - pode vir a ser renovado e atualizado em face da crescente "tercermundização" das populações do planeta, inclusive de frações daquelas que se encontram nos países do "Norte global" (SANTOS, [2000] 2001).

Nesse sentido, dada a "centralidade da periferia", Santos ([2000] 2001) reconheceu a existência de um "desafio ao Sul" - expressão que tomou de empréstimo ao ativista anticolonial e ex-presidente da Tanzânia, Julius Nyerere (THE SOUTH COMMISSION, 1992) -, desafio esse que é de natureza política, mas também, conforme bem explicitou o autor (SANTOS, 1999), de natureza epistemológica, pois as mudanças em curso na globalização atual podem acabar passando despercebidas:

(...) em função do nosso aparelho epistemológico. Todos somos de tal maneira subordinados à episteme norte-ocidental, que temos enorme dificuldade para pensar diferente. Esse é um problema para as ciências sociais latino-americanas e brasileiras. São por demais escravizadas pelo paradigma do Norte e pela política que daí decorre. Nunca pensamos o mundo a partir da América Latina. Quem entre nós, intelectuais, pensou o mundo? A gente pensa Europa, Estados Unidos e exclui a África e a Ásia. A própria construção territorial da realidade nos escapa com muita freqüência (sic) na nossa elaboração intelectual. Essa é a realidade que cobra de nós uma outra epistemologia (SANTOS, 1999, p. 37, grifo nosso).

Como se vê muito claramente, o alerta de Santos (1999) a propósito dos riscos da subordinação à episteme norte-ocidental e sobre a necessidade de construção de uma outra epistemologia, capaz de pensar o mundo a partir dos lugares e dos povos subalternizados e apta a apreender as possibilidades de mudanças que deles emergem no sentido de uma outra globalização, parecem ecoar os debates contemporaneamente levantados pelos autores descoloniais a respeito da persistência da colonialidade do saber e da importância de um projeto de 
descolonização do conhecimento que compreenda, inclusive, a própria ciência geográfica.

\section{Considerações finais}

Nos últimos anos, o "giro descolonial" tem se mostrado como uma das principais tendências contemporâneas da Geografia brasileira, contribuindo para colocar em primeiro plano, na agenda de estudos dessa ciência, questões e problemáticas relacionadas às múltiplas expressões políticas, econômicas, culturais, epistêmicas e espaciais da colonialidade e às possibilidades de construção de um saber, de uma imaginação e de uma prática geográficas descentradas, plurais e comprometidas com as resistências e lutas dos segmentos sociais, dos povos e das comunidades que mais sofrem com a exploração/opressão/dominação engendradas pelo sistema-mundo moderno-colonial e pelo capitalismo global.

Nesse contexto, o presente artigo procurou defender a ideia de que a incorporação do pensamento descolonial à ciência geográfica brasileira não pode ser encarada como um movimento de sentido único pelo qual esta última simplesmente adota, mecanicamente, as bases teóricas e os conceitos daquele primeiro, transpondo-os para o seu métier. Muito mais proveitoso seria, como também ressaltou Cruz (2017), se o pensamento descolonial também pudesse ser enriquecido, mediante aproximações, mediações e diálogos críticos, com o patrimônio intelectual acumulado pela Geografia brasileira ao longo de sua história.

As obras, os pensamentos e os legados que propomos chamar de "geografias do Sul" fazem parte desse patrimônio intelectual da ciência geográfica brasileira e apresentam um grande potencial de interlocução com as mais recentes "epistemologias do Sul", pois, assim como estas últimas, elas também tiveram na exploração/opressão/dominação coloniais e capitalistas e na especificidade da experiência histórica dos países e povos do "Sul global", seus temas privilegiados de reflexão e ação, embora apresentem entre si importantes e não negligenciáveis divergências de ordem teórica e metodológica.

Como procuramos demonstrar no decorrer do artigo, o pensamento e obra do intelectual brasileiro Milton Santos são expressões muito representativas das "geografias do Sul", pois compartilham do esforço de descentramento do locus de enunciação e de reflexão, da leitura transescalar e da atenção para com as geografizações da vida social, atributos esses que caracterizam a abordagem em referência. 
Embora fortemente influenciado pelos referenciais da ciência moderna, notadamente de matriz europeia, o pensamento miltoniano, nos diferentes momentos de sua trajetória, esteve longe de constituir um pensamento eurocêntrico, pois as realidades e as experiências que orientaram suas formulações teóricas e que inspiraram suas críticas e revisões às teorias consagradas de autores do "Norte global" foram sempre aquelas concernentes aos países, às regiões e aos lugares daquilo que, décadas atrás, costumava-se denominar de "Terceiro Mundo" e que, contemporaneamente, vem sendo chamado de "Sul global".

Ainda hoje, o legado do pensamento miltoniano continua a exercer profunda influência sobre a produção geográfica brasileira, chegando mesmo a definir uma escola de pensamento pautada em suas bases teóricas e conceituais. Os autores e obras que nelas se inspiram dão, assim, continuidade e atualidade a essa expressão das "geografias do Sul" que em muito têm contribuído para a leitura crítica das lógicas exógenas e das dialéticas endógenas do território nacional no período da globalização. Aproximando-se da matriz crítica do pensamento descolonial, bem como de muitas de suas preocupações analíticas e ético-políticas, o pensamento miltoniano, e as "geografias do Sul" de maneira mais geral, ainda aguardam um exame mais detido das interlocuções possíveis e das efetivas divergências em relação às emergentes epistemologias críticas do período contemporâneo.

\section{REFERÊNCIAS}

ANDRADE, M. C. A terra e o homem no Nordeste: contribuição ao estudo da questão agrária no Nordeste. 5. ed. São Paulo: Atlas, 1986.

ANDRADE, M. C. Uma releitura crítica da obra de Josué de Castro. In: ANDRADE, M. C. et al. Josué de Castro e o Brasil. São Paulo: Fundação Perseu Abramo, 2003. p. 73-82.

AZEVEDO, G. F. Josué de Castro e sua obra: uma interpretação. In: MACHADO, M. S.; MARTIN, A. R. (orgs.). Dicionário dos geógrafos brasileiros. Rio de Janeiro: 7 Letras, 2014. p. $67-84$.

CASTELLS, M. (org.). Imperialismo y urbanización en América Latina. Barcelona: Editorial Gustavo Gili, 1973.

CASTELLS, M. A questão urbana. 4. ed. Rio de Janeiro: Paz e Terra, [1972] 1983.

CASTRO, J. Ouvindo Josué de Castro - homem força do nosso tempo (entrevista a Araújo Dantas - 1965). In: CASTRO, A. M. (org.). Fome, um tema proibido: últimos escritos de Josué de Castro. Petrópolis: Vozes, 1984. p. 111-115. 
CASTRO, J. Homens e caranguejos. 1. ed. Rio de Janeiro: Civilização Brasileira, 2001.

CERQUEIRA-NETO, S. P. G. Epistemologias do sul e a Nova Geografia: por uma Geografia Popular no encontro entre Milton Santos e Boaventura de Sousa Santos. Cronos: Revista de Pós-Graduação em Ciências Sociais, Natal, v. 18, n. 1, p. 68-88, jan./jun. 2017.

CORRÊA, R. L. A rede de localidades centrais nos países subdesenvolvidos. Revista Brasileira de Geografia, Rio de Janeiro, ano 50, n. 1, p. 61-84, jan./mar. 1988.

CRUZ, V. C. Geografia e pensamento descolonial: notas sobre um diálogo necessário para a renovação do pensamento crítico. In: CRUZ, V. C.; OLIVEIRA, D. A. (orgs.). Geografia e giro descolonial: experiências, ideias e horizontes de renovação do pensamento crítico. Rio de Janeiro: Letra Capital, 2017. p. 15-36.

DANTAS, A. Geografia e epistemologia do sul na obra de Milton Santos. Mercator, Fortaleza, v. 13, n. 3, p. 49-61, set./dez. 2014.

FERRETTI, F.; PEDROSA, B. V. Inventing critical development: a Brazilian geographer and his Northern networks. Transactions of the Institute of British Geographers, Oxford, v. 43, n. 4, p. 703-717, dez. 2018.

HARVEY, D. A justiça social e a cidade. 1. ed. São Paulo: Hucitec, 1980.

HIERNAUX, D. El trabajo del geógrafo en el Tercer Mundo revisited. In: MENDOZA, C. (coord.). Tras las huellas de Milton Santos: una mirada latinoamericana a la geografía humana contemporánea. Ciudad de México: Anthropos Editorial, 2008. p. 14-24.

LACOSTE, Y. A geografia: isso serve, em primeiro lugar, para fazer a guerra. 19. ed. Campinas: Papirus, 1988.

MACHADO, T. Geografia e dependência: o diálogo entre Milton Santos e Ruy Mauro Marini a partir da teoria do subimperialismo. GEOgraphia, Niterói, v. 19, n. 40, p. 185- 190, 2017.

MACHADO, T. Milton Santos: a pioneer in critical geography from the global South. Finisterra, Lisboa, v. 54, n. 110, p. 175-178, 2019. [Seção] Atualização bibliográfica. Atualização bibliográfica da obra de: MELGAÇO, L.; PROUSE, C. (eds.). Milton Santos: a pioneer in critical geography from the global South. Switzerland: Springer International, 2017.

MALDONADO-TORRES, N. La descolonización y el giro des-colonial. Tabula Rasa, Bogotá, n. 9, p. 61-72, jul./dez. 2008.

MARINO, L. F. Manuel Correia de Andrade: um geógrafo voltado para as causas sociais. In: MACHADO, M. S.; MARTIN, A. R. (orgs.). Dicionário dos geógrafos brasileiros. Rio de Janeiro: 7 Letras, 2014. p. 101-117.

MELGAÇO, L.; PROUSE, C. (eds.). Milton Santos: a pioneer in critical geography from the global South. Switzerland: Springer International, 2017a.

MELGAÇO, L.; PROUSE, C. Milton Santos and the centrality of the periphery. In: MELGAÇO, L.; PROUSE, C. (eds.). Milton Santos: a pioneer in critical geography from the global South. Switzerland: Springer International, 2017b. p. 1-24.

MOREIRA, R. O pensamento geográfico brasileiro: as matrizes brasileiras. 3. ed. São Paulo: Contexto, 2010. 
NUN, J. Superpoblación relativa, ejército industrial de reserva y masa marginal. Revista Latinoamericana de Sociología, Buenos Aires, v. 5, n. 2, p. 180-225, 1969.

PEDROSA, B. V. O périplo do exílio de Milton Santos e a formação de sua rede de cooperação. História, Ciência, Saúde - Manguinhos, Rio de Janeiro, v. 25, n. 2, p. 429448, abr./jun. 2018.

QUIJANO, A. La formación de un universo marginal en las ciudades de América Latina. In: CASTELLS, M. (org.). Imperialismo y urbanización en América Latina. Barcelona: Editorial Gustavo Gili, 1973. p. 141-166.

SANTOS, M. Underdevelopment and poverty: a geographer's view. Toronto: University of Toronto, 1975.

SANTOS, M. O trabalho do geógrafo no Terceiro Mundo. São Paulo: Hucitec, 1978.

SANTOS, M. Metamorfoses do espaço habitado: fundamentos teóricos e metodológicos da Geografia. 1. ed. São Paulo: Hucitec, 1988.

SANTOS, M. Metrópole corporativa fragmentada: o caso de São Paulo. São Paulo: Nobel, 1990.

SANTOS, M. A urbanização brasileira. São Paulo: Hucitec, 1993.

SANTOS, M. Por uma economia política da cidade: o caso de São Paulo. São Paulo: Educ, 1994.

SANTOS, M. Milton Santos. Entrevistado por José Corrêa Leite. Teoria e debate, São Paulo, n. 40, p. 32-39, 1999.

SANTOS, M. Por uma outra globalização: do pensamento único à consciência universal. 6. ed. Rio de Janeiro: Record, [2000] 2001.

SANTOS, M. Elogio da lentidão. In: SANTOS, M. O País distorcido: o Brasil, a globalização e a cidadania. Org. de Wagner Costa Ribeiro. São Paulo: Publifolha, 2002. p. 162-166.

SANTOS, M. Região: globalização e identidade. In: LIMA, L. C. (org.). Conhecimento e reconhecimento: homenagem ao geógrafo cidadão do mundo. Fortaleza: EDUECE, 2003. p. $12-19$.

SANTOS, M. Entrevista. In: SANTOS, M. Entrevistado por Jesus de Paula Assis; colab. de Maria Encarnação Sposito. Milton Santos: testamento intelectual. São Paulo: Editora da UNESP, 2004. p. 11-62.

SANTOS, M. Economia espacial: críticas e alternativas. 2. ed. São Paulo: EDUSP, [1979] 2007.

SANTOS, M. O centro da cidade do Salvador: estudo de geografia urbana. 2. ed. São Paulo: EDUSP, [1959] 2008a.

SANTOS, M. O espaço dividido: os dois circuitos da economia urbana dos países subdesenvolvidos. 2. ed. São Paulo: EDUSP, [1979] 2008b.

SANTOS, M. Por uma Geografia nova: da crítica da Geografia a uma Geografia crítica. 6. ed. São Paulo: EDUSP, [1978] 2012. 
SANTOS, M. Pobreza urbana. 3. ed. São Paulo: EDUSP, [1978] $2013 a$.

SANTOS, M. Técnica, espaço, tempo: globalização e meio técnico-científico-informacional. 5. ed. São Paulo: EDUSP, [1994] 2013b.

SANTOS, M. Espaço e método. 5. ed. São Paulo: EDUSP, [1985] 2014a.

SANTOS, M. O espaço do cidadão. 7. ed. São Paulo: EDUSP, [1987] 2014b.

SANTOS, M. A natureza do espaço: técnica e tempo, razão e emoção. 4. ed. São Paulo: EDUSP, [1996] 2014c.

SANTOS, M.; SILVEIRA, M. L. O Brasil: território e sociedade no início do século XXI. 16. ed. Rio de Janeiro: Record, [2001] 2012.

SIMONI-SANTOS, C. Da marginalidade à segregação: contribuições de uma teoria urbana crítica. Economía, sociedad y territorio, Zinacantepec, v. 17, n. 55, p. 619-646, 2017.

SOUSA SANTOS, B. Para além do pensamento abissal: das linhas globais a uma ecologia de saberes. In: SOUSA SANTOS, B.; MENESES, M. P. (orgs.). Epistemologias do Sul. Coimbra: Almedina, 2009. p. 21-71.

SOUSA SANTOS, B. Introducción: las epistemologías del Sur. In: CIDOB (org.). Formasotras. Saber, nombrar, narrar, hacer. Barcelona: CIDOB Ediciones, 2012. p. 9-22. Disponível em: http://www.boaventuradesousasantos.pt/media/Formas-Otras_Dec2011.pdf. Acesso em: 14 maio 2019.

THE SOUTH COMMISSION. The challenge to the South - the report of the South Commission. New York: Oxford University Press, 1992.

\section{NOTAS DE AUTOR}

\section{CONTRIBUIÇÃO DE AUTORIA}

Gabriel Carvalho da Silva Leite - Concepção e elaboração do manuscrito. Coleta e análise de dados. Participação ativa da discussão dos resultados. Revisão e aprovação da versão final do trabalho.

Saint-Clair Cordeiro da Trindade Júnior - Concepção e elaboração do manuscrito. Coleta e análise de dados. Participação ativa da discussão dos resultados. Revisão e aprovação da versão final do trabalho.

\section{FINANCIAMENTO}

O artigo sistematiza resultados parciais de investigação do projeto de pesquisa "Geografias e epistemologias do sul: Amazônia, olhares críticos em perspectiva", desenvolvido como parte das atividades do segundo autor como bolsista de produtividade de pesquisa do Conselho Nacional de Desenvolvimento Científico e Tecnológico (CNPq) - Processo CNPq 305080/2018-0 -, entidade do governo brasileiro voltada para o desenvolvimento científico e tecnológico.

\section{CONSENTIMENTO DE USO DE IMAGEM}

Não se aplica.

\section{APROVAÇÃO DE COMITÊ DE ÉTICA EM PESQUISA \\ Não se aplica.}

\section{CONFLITO DE INTERESSES}

Não se aplica.

\section{LICENÇA DE USO}

Este artigo está licenciado sob a Licença Creative Commons CC-BY. Com essa licença você pode compartilhar, adaptar, criar para qualquer fim, desde que atribua a autoria da obra. 


\section{HISTÓRICO}

Recebido em: 01-02-2020

Aprovado em: 28-05-2020 